\title{
Pressure-Induced Shifts in Trophic Linkages in a Simplified Aquatic Food Web
}

\section{OPEN ACCESS}

Edited by:

Peter Thorburn,

Commonwealth Scientific and Industrial Research Organisation (CSIRO), Australia

Reviewed by:

Andrey S. Zaitsev, Justus Liebig Universität Gießen, Germany

Vesna Gagic,

Commonwealth Scientific and Industrial Research Organisation (CSIRO), Australia

*Correspondence: Maarten Schrama m.j.j.schrama@cml.leidenuniv.nl

Specialty section:

This article was submitted to Agroecology and Land Use Systems, a section of the journal Frontiers in Environmental Science

Received: 10 August 2017 Accepted: 30 October 2017 Published: 04 December 2017

Citation

Schrama M, Barmentlo SH, Hunting $E R$, van Logtestijn RSP, Vijver MG and van Bodegom PM (2017) Pressure-Induced Shifts in Trophic Linkages in a Simplified Aquatic Food Web.

Front. Environ. Sci. 5:75 doi: 10.3389/fenvs.2017.00075

\begin{abstract}
Maarten Schrama ${ }^{1,2 *}$, S. Henrik Barment/o ${ }^{1}$, Ellard R. Hunting ${ }^{1}$, Richard S. P. van Logtestijn ${ }^{3}$, Martina G. Vijver ${ }^{1}$ and Peter M. van Bodegom ${ }^{1}$

${ }^{1}$ Conservation Biology, Institute of Environmental Sciences, Leiden University, Leiden, Netherlands, ${ }^{2}$ Soil and Ecosystem Ecology Group, University of Manchester, Manchester, United Kingdom, ${ }^{3}$ Systems Ecology, Department of Ecological Science, Faculty of Earth and Life Sciences, Vrije Universiteit Amsterdam, Amsterdam, Netherlands
\end{abstract}

It is essential to understand effects of existing and emerging anthropogenic stressors on the structure of aquatic food webs in more natural settings, to obtain realistic predictions on how they can affect major ecosystem properties and functioning. We therefore examined whether (1) realistic concentrations of key agricultural pesticides and nutrients induce shifts in trophic linkages (2) observed changes in trophic linkages are qualitatively different between the green (algal-based) and brown (detritus-based) part of the food web. To this end, we exposed a simplified, yet realistic freshwater invertebrate community to environmentally relevant concentrations of three anthropogenic pressures (eutrophication; the herbicide terbuthylazine; and the insecticide imidacloprid) in a full factorial mesocosm design. Trophic linkages and the changes therein were assessed measuring stable isotopes of natural carbon and nitrogen. Results show that the green and brown part of the food web react qualitatively different to interacting pressures. Whereas, herbivorous species react mainly to the nutrients and herbicides and the synergistic interaction between these, species in the detritivore part of the food web were affected by insecticide applications and interactions with nutrients. These results suggest that agricultural pressures can induce shifts in trophic linkages, but that they can have contrasting effects on the different parts of the food web. Such antagonistic and synergistic interactions can provide powerful explanations for observed responses of ecosystems to interacting stressors. These findings may have important implications for our understanding on interactions of agricultural stressors and their propagation in aquatic food webs.

Keywords: stable isotopes, imidacloprid, terbuthylazine, multiple stressors, anthropogenic pressures, interaction web, green web, brown web

\section{INTRODUCTION}

Aquatic ecosystems harbor a diverse array of organisms that interact across trophic levels (Wallace et al., 1997). As species in natural communities are strongly interdependent (Pimm et al., 1991), effects of a pressure on a given species can be expected to resonate through the entire food web (Gessner et al., 2010; Vörösmarty et al., 2010). Hence, to generate realistic predictions on how existing and emerging anthropogenic stressors can affect major ecosystem properties and impede 
ecosystem functioning, an understanding of their effects on trophic linkages is required (Moore et al., 2005; Jabiol et al., 2013).

A major pressure on aquatic communities is the use of agricultural chemicals (nutrients and pesticides) which are used to increase and protect crop yield (Helweg et al., 2003). Aquatic animals can react to such pollutants by altering their food source, leading to changes in predation efficiency (Smith and Weis, 1997; Schulz and Dabrowski, 2001), bioturbation (Hinkle-Conn et al., 1998; Hunting et al., 2013) and nutrient cycling (Fleeger et al., 2003). Such alterations in trophic linkages can be regarded as rippling effects in food webs which may result in ecosystemwide effects and subsequently affect ecosystem functioning and the services it provides (Fleeger et al., 2003; Corvalan et al., 2005). However, how anthropogenic pressures propagate through trophic linkages in aquatic food webs and inherent effects on ecosystem processes remains poorly understood.

To date, the vast majority of studies focusing on the effect of pesticides have evaluated the effect of a single chemical substance on survival of individuals, as this is the common approach in ecotoxicological risk assessment (van den Brink, 2006; Gessner and Tlili, 2016). Most ecosystems however, particularly aquatic ecosystems bordering agricultural land, are exposed to a myriad of interacting stressors (Ormerod et al., 2010; Gagic et al., 2017), making it important to predict their direct and indirect effects on networks of trophic linkages. Little doubt exists that the effects of these substances (e.g., of bioaccumulation and biomagnification, effects on trophic linkages) are not necessarily additive (Côté et al., 2016), which is traditionally assumed by models that assess effects of mixtures of contaminants (Altenburger et al., 2000; Backhaus et al., 2004). Another glaring issue is that most traditional studies to date have typically ignored sublethal effects such as changes in resource preference that further mediate the effects of abiotic factor on species interactions and identities (Rohr et al., 2006; van den Brink, 2006). The traditional approach thus presents a considerable oversimplification of real environmental conditions (Cairns, 1983; Kimball and Levin, 1985; Calow and Forbes, 2003; Rohr et al., 2006; van den Brink, 2006; Vijver et al., 2017), thereby warranting experimental studies that assess the effect of multiple stressors on trophic linkages in aquatic food webs.

Pesticides and herbicides affect different components of aquatic ecosystems, in which herbicides are more likely to indirectly affect herbivorous organisms, and insecticides to directly affect (sensitive) invertebrates. It is thus conceivable that herbicides and pesticides differentially affect the structure and trophic linkages of aquatic food webs. This study therefore aims to evaluate whether (1) environmentally relevant concentrations of key agricultural pesticides and nutrients, and interactions between these, induce shifts in trophic linkages, and (2) observed changes in trophic linkages are qualitatively different between the green (algal-based) and brown (detritus-based) part of the food web. To this end, we carried out a full factorial outdoor mesocosm experiment to investigate the interactive effects of three chemical stressors (herbicide, insecticide, and excess nutrients) at environmentally realistic concentrations on the trophic linkages within a simplified, model aquatic food web.

\section{METHODS}

To adequately separate the effect of agricultural pressures we used a full factorial design containing an aquatic community composed of commonly co-occurring species, in which we mimicked all combinations of three different realistic pressures: of a single herbicide and a single insecticide, in presence and absence of agricultural nutrients and the interactions between all three factors. We applied the following eight different treatments in a randomized fashion, each with a sample size of six: (I) imidacloprid, (II) terbuthylazine, (III) nutrients, (IV) imidacloprid and terbuthylazine, (V) imidacloprid and nutrients, (VI) terbuthylazine and nutrients, (VII) imidacloprid, terbuthylazine and nutrients, and (VIII) a control with no added substances. The insecticide and herbicide of choice were imidacloprid (CAS No. 138261-41-3, purity 99.7\%) and terbuthylazine (CAS No. 5915-41-3, purity 99.4\%) respectively, purchased from Sigma Aldrich (Zwijndrecht, The Netherlands). These chemical substances were selected for the following reasons: First, they are representative for a group of insecticides (nitroguanidines, which affect the nervous system) and herbicides (triazines, which are photosystem II -inhibitors), which are commonly used groups of pesticides. Second, both types of pesticides are used across a range of intensively managed agricultural systems and present in high concentrations in surface water in the Netherlands (Pesticide Atlas, 2015).

\section{Experimental Setup}

The experiment was set up in the experimental garden of the Hortus Botanicus in Leiden, The Netherlands and was conducted in $4865 \mathrm{~L}$ polyethylene tubs, hereafter called mesocosms. To mimic natural pond conditions and to prevent the mesocosms from unnatural heating, tubs were placed $30 \mathrm{~cm}$ into the soil. The $8 \mathrm{~cm}$ of the mesocosms that was raised above the ground was covered in reflective tape in order to reflect sunlight to prevent heating. Additionally, mesocosms were tightly covered with 50\% shadow cloth nets to prevent colonization, escape and excessive heating. In order to provide the animals with oxygen and to homogenize the water column, each mesocosm was aerated using a 5 watt aquarium pump.

In order to set up an adequate sediment layer, a combination of finely ground hay and fine-grained, ignited quartz sand as mineral substrate (grain size: $0.1-0.5 \mathrm{~mm}$ ) was used. First, $500 \mathrm{~g}$ of finely cut dry hay $(5 \mathrm{~cm})$ was pre-soaked and mixed with $12.5 \mathrm{~kg}$ moist sand, which was placed at the bottom of the mesocosms. After placement of the sediment layer, $\sim 36 \mathrm{~L}$ of copper-free tap water was added. Copper removal was conducted by filtering tap water with active carbon for 14 days. Subsequently, each mesocosm received $4 \mathrm{l}$ of filtered ditch water (mesh width $0.5 \mathrm{~mm}$ ) that was mixed first in a large volume and was added to inoculate the mesocosms with a natural species composition of unicellular organisms. The water column and sediment layer were left for 1 week in order to allow the microbial community to establish.

The food web composition of the species in the experiment consisted of 10 commonly co-occurring species in natural and agricultural freshwater ecosystems in the Netherlands (Ieromina 
et al., 2016) of a variety of feeding types; (I) grazer, (II) shredder, (III) filter-collector, (IV) predator, and (V) gatherer/collector (Ieromina et al., 2016). Species were assigned to trophic groups based on literature. This resulted in the following three trophic groups: (1) herbivorous diet: Cyclops sp., Cloeon dipterum and Daphnia magna (Ahlgren et al., 1990; Santer and Van Den Bosch, 1994) (2) Detritivore diet: Tubifex sp., Chironomus riparius, Culex pipiens, and Asellus aquaticus (Graça et al., 1993; David et al., 2000), (3) Mixed diet: Sigara striata, Lymnaea stagnalis (Klecka and Boukal, 2012; Groendahl and Fink, 2016), (4) Predator group consisting of a single species (Notonecta glauca). Notonecta species are generalist predators that can potentially have large impacts on pond community structure (Cockrell, 1984; Wilbur and Dec, 1997; Klecka and Boukal, 2012) and are known to prey on all the species in the introduced community except for Tubifex sp. and only very rarely on L. stagnalis.

Species were either grown in lab culture or were collected from non-polluted field sites. To be able to trace the change in stable isotope levels during the experiment we added individuals of most species as juveniles. A full description of species and their numbers is presented in Table 1. Seven days after setting up the sediments, non-predacious animals were placed in the mesocosms. One day later, we added the predators. Herbicide, insecticide and fertilizer treatments were installed 1 day after predator additions.

The following nominal concentrations were used: $3.5 \mu \mathrm{g} / \mathrm{L}$ terbuthylazine and $4.0 \mu \mathrm{g} / \mathrm{L}$ imidacloprid, which were based on realistic concentrations in Dutch surface waters (Pesticide Atlas, 2015). The substances were dissolved in demineralized water in glass bottles and mixed by magnetic stirring. In addition, we added $6.16 \mathrm{~mL}$ of soluble plant feed in nutrient treatments (Nitrogen: Phosphorus: Potassium 7:4:7 (Pokon Naturado), in order to reach nominal concentrations of soluble phosphorus of $3.8 \mathrm{mg} / \mathrm{L}$, which are realistic for Dutch surface waters and were previously shown to lead to high algal production (Ieromina et al., 2016). A second addition of insecticides, herbicides and nutrients, in equal concentrations to the first application, was conducted halfway through the experiment $(t=18, t=$ time in days), thus mimicking a biweekly application of substances.
In order to further promote homogenization of the water column (next to continuous aerating of the water), all substances were added to the mesocosms in large volumes. Presence of either terbuthylazine (Omegam Laboratoria BV (Amsterdam, The Netherlands) and imidacloprid (Wageningen University, Wageningen, The Netherlands) was measured using liquid chromatography-tandem mass spectrometry (LC-MS/MS) on a weekly basis. The measured concentrations showed a gradual decrease in pesticide concentrations, confirming expectations (Electronic Appendix Figure S1). The time weighted average for terbuthylazine was $2.04 \mu \mathrm{g}^{-1}$ and for imidacloprid $2.9 \mu \mathrm{gl}^{-1}$. Also for nutrients we found that actual concentrations were lower than nominal concentrations, indicating uptake of nutrients.

The experiment was harvested after 35 days. To retrieve all macrofauna, the entire mesocosm was filtered through two sieves, one for the larger specimen (mesh size $2 \mathrm{~mm}$ ) and one for the smaller specimen (mesh size $0.106 \mathrm{~mm}$ ). All animals except for D. magna and Cyclops sp. were collected by hand with forceps and pipettes. Individuals of a single species were pooled per mesocosm in a single sample tube. In addition, a $20 \times 10 \mathrm{~cm}$ plot of periphyton was scraped from the side of the mesocosm interior that received the most sun hours per day. Algal quantity in the mesocosm was insufficient for stable isotope analyses.

\section{Stable Isotope Analyses}

To investigate effects of the three different pressures on food web properties, we used carbon and nitrogen stable isotopes. Stable isotopes of carbon are excellent tools to study such changes in food web organization because there is a difference between the $\delta^{13} \mathrm{C} / \delta^{12} \mathrm{C}$ of $\mathrm{C} 3$ detritus and freshwater algae (Hamilton and Lewis, 1992). Changes in $\delta^{13} \mathrm{C} / \delta^{12} \mathrm{C}$ thus reflect changes in the utilization of different carbon sources by the respective trophic groups and taxa. Shifts from algal feeding to detritus feeding are expected to result in an increase in $\delta \mathrm{C}^{13}$ levels. Heavy nitrogen isotopes $\left(\delta^{15} \mathrm{~N}\right)$ accumulate in the trophic chain (Hobson and Welch, 1992; Post, 2002), and can thus inform about effects of treatments on trophic structure and position. A change in $\delta^{15} \mathrm{~N}$ can expected to happen when there is a shift in $\mathrm{N}$ source to the base of the food web, for example when algae start using different

TABLE 1 | Characteristics of species and numbers used in the mesocosm experiment.

\begin{tabular}{|c|c|c|c|c|c|}
\hline Species & Food source & Feeding strategy & Origin & Nr. added & Life stage \\
\hline Daphnia magna & Algae & Filter-collector & Lab culture, Leiden University & 78 & Neonate \\
\hline Lymnaea stagnalis & Detritus & Grazer/Shredder & Lab culture, VU University Amsterdam & 5 & Juvenile \\
\hline Cyclops sp. & Algae & Filter-collector & Collected from field & 60 & Juvenile \\
\hline Cloeon dipterum & Algae/detritus & Filter-collector/Shredder & Collected from field & 15 & Juvenile, 2nd inst. \\
\hline Culex pipiens & Detritus & Gatherer/Filter-collector & Collected from field & 12 & Juvenile, 3rd inst. \\
\hline Chironomus riparius & Detritus & Shredder & Lab culture, commercial & 50 & Juvenile, 3rd inst. \\
\hline Asellus aquaticus & Detritus & Shredder & Collected from field & 15 & Juvenile \\
\hline Tubifex sp. & Detritus & Collector/Gatherer & Lab culture, commercial & 220 & Mix juvenile/adult \\
\hline Sigara striata & Algae/Macrofauna & Gatherer/Predator & Collected from field & 12 & Adult \\
\hline Notonecta glauca & Macrofauna & Predator & Collected from field & 2 & Adult \\
\hline
\end{tabular}

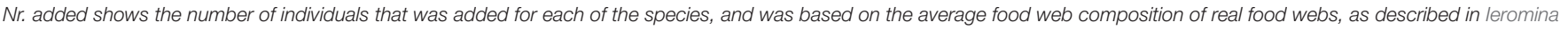
et al., 2016. Species are grouped by food source. For holometabolic insects, juvenile stage is given. 
$\mathrm{N}$ sources or as a result of shift in carnivore feeding preference, which could for instance result from weakened prey/intermediate trophic levels.

After the harvesting the experiment, all sampling tubes were stored at $-20^{\circ} \mathrm{C}$ prior to further processing. For the largest species ( $N$. glauca and L. stagnalis), we used only part of the body for stable isotope analysis. For N. glauca, we used the pronotum, which was separated from the remainder of the body manually, and for L. stagnalis, we used only the foot of the snail. We expected that, as a result of growth, these parts would most readily reflect treatment-induced changes in carbon and nitrogen isotopes. Samples were freeze-dried, ground and weighed in tin cups prior to stable isotope analysis. Large samples of N. glauca, L. stagnalis, and S. striata were ground for $5 \mathrm{~min}$. Smaller samples of C. dipterum, A. aquaticus, and periphyton were ground for $1.5 \mathrm{~min}$, using a ball mill (Retsch Technology $\mathrm{GmbH}$, Haan, Germany). Samples of the remaining species were small enough to be used entirely. We used $1.0( \pm 0.2) \mathrm{mg}$ of each sample of a single species from a single mesocosm, which were weighed into $5 \times 8 \mathrm{~mm}$ tin capsules. The stable isotopes were measured using an elemental analyser (NC2500; ThermoQuest Italia, Rodana, Italy) coupled with an isotope ratio mass spectrometer (Delta Plus; Thermo-Quest Finnigan, Bremen, Germany) at the VU University Amsterdam. For calibration, USGS 40 and USGS 41 were used. The reproducibility of the $\delta^{13} \mathrm{C}$ and $\delta^{15} \mathrm{~N}$ analysis determined by repeated analysis of an internal standard (Bovine liver, NIST $1577 \mathrm{c})$ was within $0 \cdot 15 \%(n=3)$. Stable isotope abundance was expressed using the $\delta$ notation:

$$
\delta X(\%)=R_{\text {sample }}-R_{\text {standard }} / R_{\text {standard }} \times 1000,
$$

where $\mathrm{X}$ represents the ${ }^{13} \mathrm{C}$ content and $R_{\text {sample }}$ and $R_{\text {standard }}$ denote the $\delta^{13} \mathrm{C} / \delta^{12} \mathrm{C}$ ratios of the sample and the standard Vienna PeeDee Belemnite (VPDB), respectively. For $\mathrm{N}, X$ represents the $\delta^{15} \mathrm{~N}$ content and $R_{\text {sample }}$ and $R_{\text {standard }}$ denote the $\delta^{15} \mathrm{~N} / \delta^{14} \mathrm{~N}$ ratios of the sample and the standard air, respectively.

\section{Statistics}

Statistical analyses were performed with Rstudio, version 0.99.902 (R version 3.3.0) and Statistica 10 (Stat Soft Inc., Tulsa, USA). To illustrate food web relationships between single species, linear least square regressions were carried out for both $\mathrm{C}$ and $\mathrm{N}$ isotopes. A multiple regression analysis of the nitrogen isotopes was carried out to detect the likely food sources of $A$. aquaticus in the various treatments (species within $3 \% \mathrm{~N}$ from $A$. aquaticus: S. striata, C. dipterum, periphyton). For the analysis of changes in stable isotope composition within green and brown parts of the food web, estimations for species were averaged within trophic groups, by taking the average of the species in each of the trophic groups. We tested the single and combined effects of the agricultural chemicals on nitrogen and carbon isotopes of each species and of the entire trophic group by means of factorial ANOVA (type-II sum of squares). The factors tested were imidacloprid (2 levels; yes/no), terbuthylazine (2 levels; yes/no), nutrients (2 levels; yes/no) and all possible combinations of these factors. Stable isotopes of the different species/trophic groups were always (and only) used as response variables in these analyses. Assumptions for homogeneity of variances as well as normality of residuals were met.

\section{RESULTS}

\section{Effects on Trophic Structure}

All species survived until the end of the experiment, with the exception of dipteran larvae C. pipiens, and C. riparius, most likely as a result of predation by $N$. glauca (Klecka and Boukal, 2012). These are therefore excluded from the remainder of the results and discussion.

As expected, we found that, across all treatments, $\delta^{13} \mathrm{C} / \delta^{12} \mathrm{C}$ ratios differ markedly between species, thus indicating different food preference between species (Figure 1). Similarly, we find different $\delta^{15} \mathrm{~N} / \delta^{14} \mathrm{~N}$ ratios between species, indicating different trophic levels (Figure 1). For both $\mathrm{N}$ and $\mathrm{C}$ stable isotopes, positive correlations were observed between a number of species (C. dipterum, D. magna, Cyclops sp., L. stagnalis, and periphyton) (Tables 2,3 ), suggesting a similar reaction to changing environmental conditions or trophic interactions. In contrast, a negative correlation was found between $S$. striata and N. glauca, for both nitrogen and carbon isotopes (Tables 2, 3), thus indicating possible competition between these species.

\section{Effect of Treatments on Base of Food Web}

The nutrients that were added to the treatments had a $\delta^{15} \mathrm{~N} / \delta^{14} \mathrm{~N}$ ratio that was $>3 \%$ o lower than the periphyton, indicating that the periphyton used this food source. It was not possible to determine the stable carbon isotope ratio of added inorganic nutrients, because they contained only trace amounts of carbon. Periphyton $\delta^{15} \mathrm{~N} / \delta^{14} \mathrm{~N}$ was positively affected by insecticide additions $\left[F_{(1,26)} 4.3 ; P=0.05\right]$, and herbicide additions $\left[F_{(1,26)} 9.2 ; P=0.005\right]$ and was negatively affected by nutrient additions $\left[F_{(1,26)} 8.5 ; P=0.007\right]$. Carbon isotope ratios for periphyton were positively affected by the nutrient treatment $\left[F_{(1,26)} 9.7, P=0.004\right]$.

\section{Effects of Treatments on the Green Web}

When averaged over all species, herbivores exhibited a decrease in $\delta^{15} \mathrm{~N} / \delta^{14} \mathrm{~N}$ ratio when exposed to nutrients $\left[F_{(1,40)} 25.6\right.$, $P<0.0001$; Figure 2A]. The other treatments (herbicides, insecticides) had no significant main effect on the $\delta^{15} \mathrm{~N} / \delta^{14} \mathrm{~N}$ ratio of herbivores. Carbon isotopes for the herbivores showed a significant main effect of nutrients $\left[F_{(1,40)} 16.4 P<\right.$ 0.001 ] and a significant interaction effect of herbicides and nutrients $\left[F_{(1,40)} 7.6, P=0.008\right.$; Figure $\left.2 B\right]$. Insecticides had a marginally significant positive effect on the carbon isotope ratio of the herbivore channel $\left[F_{(1,40)} 3.2, P=0.08\right]$. Herbivore species exhibited changes in nitrogen isotopes as a result of herbicide and nutrient additions. For Cyclops sp. and D. magna, nutrient additions lead to significantly decreased $\delta^{15} \mathrm{~N} / \delta^{14} \mathrm{~N}$ ratios [Cyclops: $F_{(1,38)} 10.0 ; P=0.003 ;$ D. magna: $F_{(1,28)} 5.2$, $P=0.03]$. Carbon isotope ratios of herbivore species also changed in response to the various treatments. For Cyclops $s p$, we found a significantly negative effect of nutrients on $\delta^{13} \mathrm{C} / \delta^{12} \mathrm{C}$ ratio $\left[F_{(1,38)} 9.8, P=0.003\right]$ and an interaction effect between 

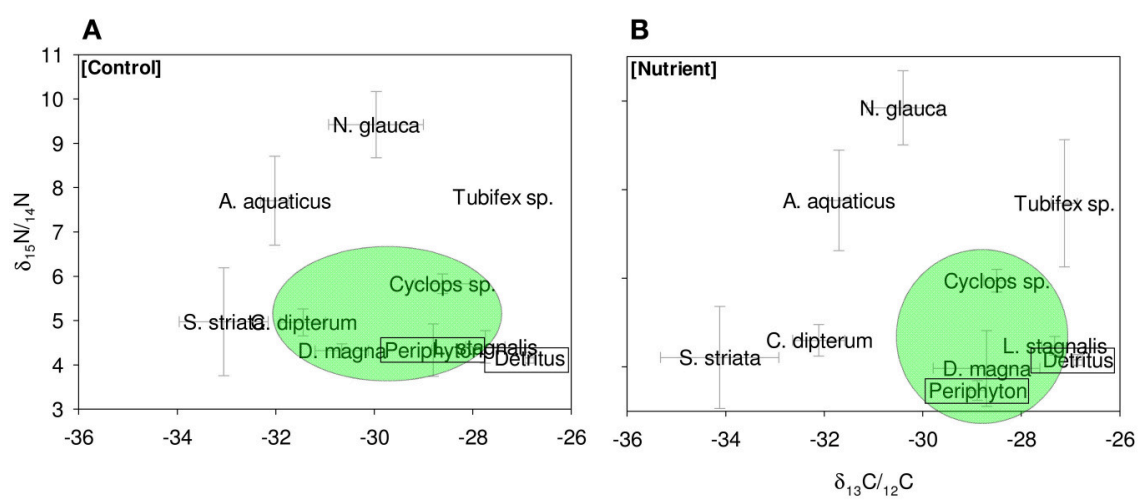

$$
\text { C }
$$

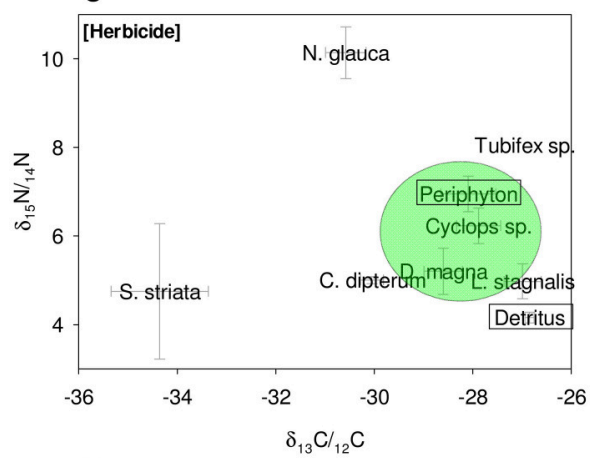

D
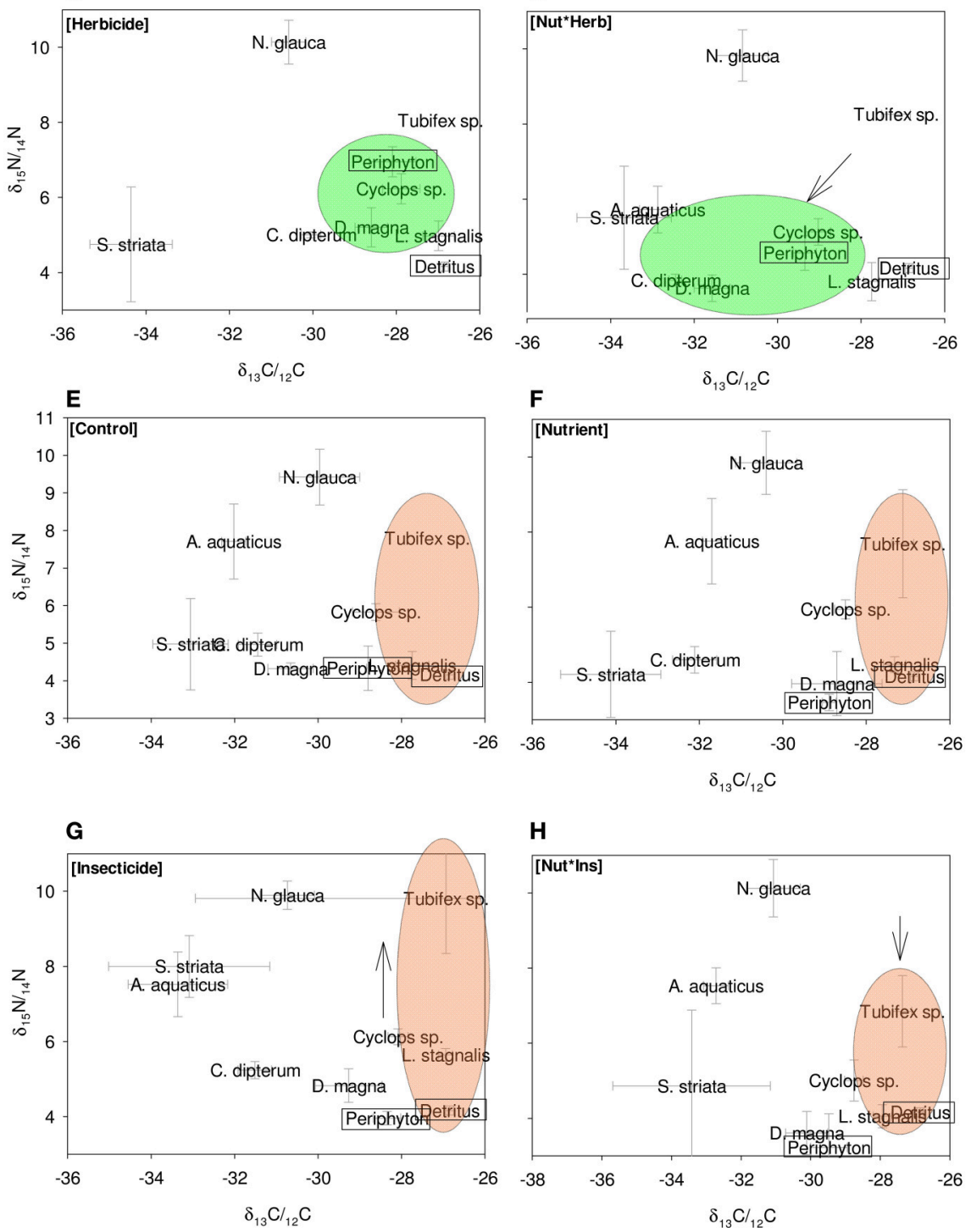

H

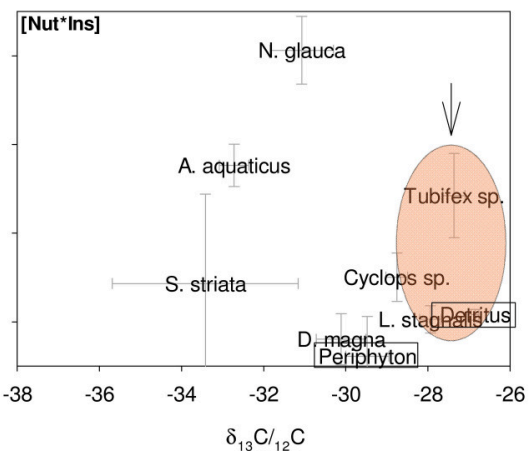

FIGURE 1 | Eight panels showing the most important changes in food webs. (A-D) show effects of the nutrient and herbicide treatment, and interaction between these the on herbivore part of the food web. (E-H) Show food webs in nutrient and insecticide treatment and interaction between these, and the effect on the detritivore part of the food web. Green circles in (A-D) indicate the herbivore energy channel; brown circles in (E-H) indicate the detritivore energy channel. Arrows indicate significant effects of treatments on the herbivore and detritivore channel. 
TABLE 2 | Pairwise correlation coefficients between nitrogen isotopes of all species in the experiment.

\begin{tabular}{|c|c|c|c|c|c|c|c|c|c|}
\hline$\delta N 15 / \delta N 14$ & Notonecta & Sigara & Cloeon & Daphnia & Zooplankton & Periphyton & Lymnea & Asellus & Tubifex \\
\hline Notonecta & & $-0.49^{\star \star \star}$ & NS & NS & NS & NS & NS & NS & NS \\
\hline Sigara & $-0.49^{\star \star \star}$ & & NS & NS & NS & NS & NS & NS & NS \\
\hline Cloeon & NS & NS & & $0.29^{+}$ & $0.48^{\star}$ & $0.25^{+}$ & NS & $0.69^{\star \star \star}$ & NS \\
\hline Daphnia & NS & NS & $0.29^{+}$ & & $0.69^{\star \star \star}$ & $0.24^{+}$ & $0.39^{*}$ & NS & NS \\
\hline Zooplankton & NS & NS & $0.48^{\star}$ & $0.69^{\star \star \star}$ & & $0.49^{\star \star}$ & $0.42^{\star \star \star}$ & NS & NS \\
\hline Periphyton & NS & NS & $0.25^{+}$ & $0.24^{+}$ & $0.49^{\star \star}$ & & $0.22^{+}$ & NS & $0.45^{\star}$ \\
\hline Lymnea & NS & NS & NS & $0.39^{\star}$ & $0.42^{\star \star \star}$ & $0.22^{+}$ & & NS & NS \\
\hline Asellus & NS & NS & $0.69^{\star \star \star}$ & NS & NS & NS & NS & & NS \\
\hline Tubifex & NS & NS & NS & & NS & $0.45^{\star}$ & NS & NS & \\
\hline
\end{tabular}

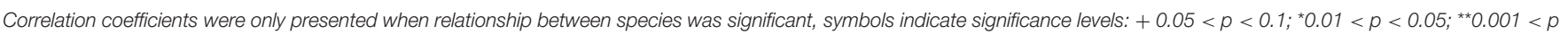
$<0.01 ;{ }^{* \star *} p<0.001 ;$ NS, not significant.

TABLE 3 | Pairwise correlation coefficients between carbon isotopes of all species in the experiment.

\begin{tabular}{|c|c|c|c|c|c|c|c|c|c|}
\hline$\delta \mathrm{C} 13 / \delta \mathrm{C} 12$ & Notonecta & Sigara & Cloeon & Daphnia & Zooplankton & Periphyton & Lymnea & Asellus & Tubifex \\
\hline Notonecta & & $-0.35^{\star}$ & NS & $0.35^{\star}$ & NS & NS & NS & NS & NS \\
\hline Sigara & $-0.35^{\star}$ & & NS & NS & NS & NS & NS & NS & NS \\
\hline Cloeon & NS & NS & & $0.86^{\star \star \star}$ & $0.62^{\star \star}$ & $0.61^{* *}$ & $0.71^{\star \star *}$ & $0.49^{\star}$ & NS \\
\hline Daphnia & $0.35^{\star}$ & NS & $0.86^{\star \star *}$ & & $0.60^{\star * *}$ & $0.36^{+}$ & $0.58^{\star \star}$ & NS & $0.22^{+}$ \\
\hline Zooplankton & NS & NS & $0.62^{\star \star}$ & $0.60^{* \star *}$ & & $0.42^{*}$ & $0.55^{\star \star \star}$ & NS & NS \\
\hline Periphyton & NS & NS & $0.61^{\star \star}$ & $0.36^{+}$ & $0.42^{*}$ & & $0.51^{\star \star}$ & NS & NS \\
\hline Lymnea & NS & NS & $0.71^{\star \star \star}$ & $0.58^{\star *}$ & $0.55^{\star \star \star}$ & $0.51^{* *}$ & & NS & $0.36^{+}$ \\
\hline Asellus & NS & NS & $0.49^{\star}$ & NS & NS & NS & NS & & NS \\
\hline Tubifex & NS & NS & NS & $0.22^{+}$ & NS & NS & $0.36^{+}$ & NS & \\
\hline
\end{tabular}

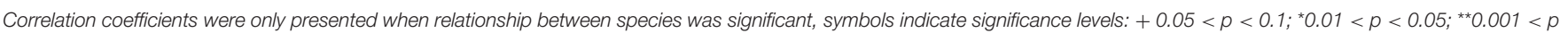
$<0.01 ;{ }^{* \star *} p<0.001 ;$ NS, not significant.

herbicides and nutrients $\left[F_{(1,38)} 9.8, P=0.004\right]$, where the effect of nutrients was larger when herbicides were added $\left[F_{(1,38)}\right.$ 4.0, $P=0.05$ ]. For D. magna, no effect of any single stressor was found, only an interaction effect between herbicides and nutrients $\left[F_{(1,27)} 5.2, P=0.03\right]$, as well as an interaction effect between nutrients, herbicides and insecticides $\left[F_{(1,27)} 6.1\right.$, $P=0.02]$.

\section{Effects on the Brown Web, $\mathrm{N}$ Isotopes}

The $\delta^{15} \mathrm{~N} /{ }^{14} \mathrm{~N}$ ratio of the entire group of detritivores group was significantly affected by the insecticide * nutrients treatment $\left[F_{(1,40)} 5.6290, P=0.02\right.$; Figure 2C]; where insecticides increase the $\delta^{15} \mathrm{~N} / \delta^{14} \mathrm{~N}$ ratio, but only in absence of nutrients. Carbon isotopes in the detritivore group were only affected by insecticide presence, where $\delta^{13} \mathrm{C} / \delta^{12} \mathrm{C}$ levels decreased when insecticides were present $\left[F_{(1,35)} 4.7, P=0.03\right.$; Figure 2D].

Within the detritivore guild, nitrogen isotope ratios were only significantly affected by the treatments for L. stagnalis, whereas A. aquaticus and Tubifex sp. showed no significant response. A significant, negative main effect of nutrients on the $\delta^{15} \mathrm{~N} / \delta^{14} \mathrm{~N}$ ratio of $L$. stagnalis was found $\left[F_{(1,40)} 20.3\right.$, $P<0.0001]$ whereas insecticide additions had a positive effect $\left[F_{(1,40)} 3.5820 ; \quad P=0.05\right]$ on $\delta^{15} \mathrm{~N} / \delta^{14} \mathrm{~N}$-levels of L. stagnalis. Trophic position was also affected by the interaction between herbicides, insecticides and nutrients $\left[F_{(1,40)} 8.1\right.$, $P=0.007]$.

\section{Effects on the Brown Web, C Isotopes}

Overall, detritivore species had $3.3 \%$ higher $\delta^{13} \mathrm{C} / \delta^{12} \mathrm{C}$ ratios than herbivore species (Figure 1), thus confirming that food preferences were different between these functional groups. However, this was not the case for $A$. aquaticus; carbon isotopes for this species were significantly lower and the $\delta^{15} \mathrm{~N} / \delta^{14} \mathrm{~N}$ ratio of $A$. aquaticus was almost an entire trophic level [2.6-3.1\%; one trophic level generally amounts to $3.4 \%$ (Post, 2002)] higher than the other primary consumers (Figure 1). This indicates that this species may have consumed food sources other than the hay debris. A multiple regression analysis of the nitrogen isotopes of the likely food sources of A. aquaticus (species within 3\%o from A. aquaticus: S. striata, C. dipterum, periphyton) indicated that $C$. dipterum may have composed a likely food source for this species [Electronic Appendix, Table 1; $F_{(1.21)}$ $9.4 \mathrm{P}$ 0.02]. A pairwise correlation between A. aquaticus and C. dipterum showed a significant positive relationship between $C$. dipterum and $A$. aquaticus for both nitrogen isotopes and carbon isotopes (Figures 3A,B), thus suggesting that $A$. aquaticus might have had a diet partly composed of dead individuals of C. dipterum.

\section{Mixed Feeders and Predators}

We found no significant effect of nutrient and pesticide treatment on the average $\delta^{15} \mathrm{~N} / \delta^{14} \mathrm{~N}$ level of mixed feeders. Within this guild, nutrients had a negative effect on carbon isotope 

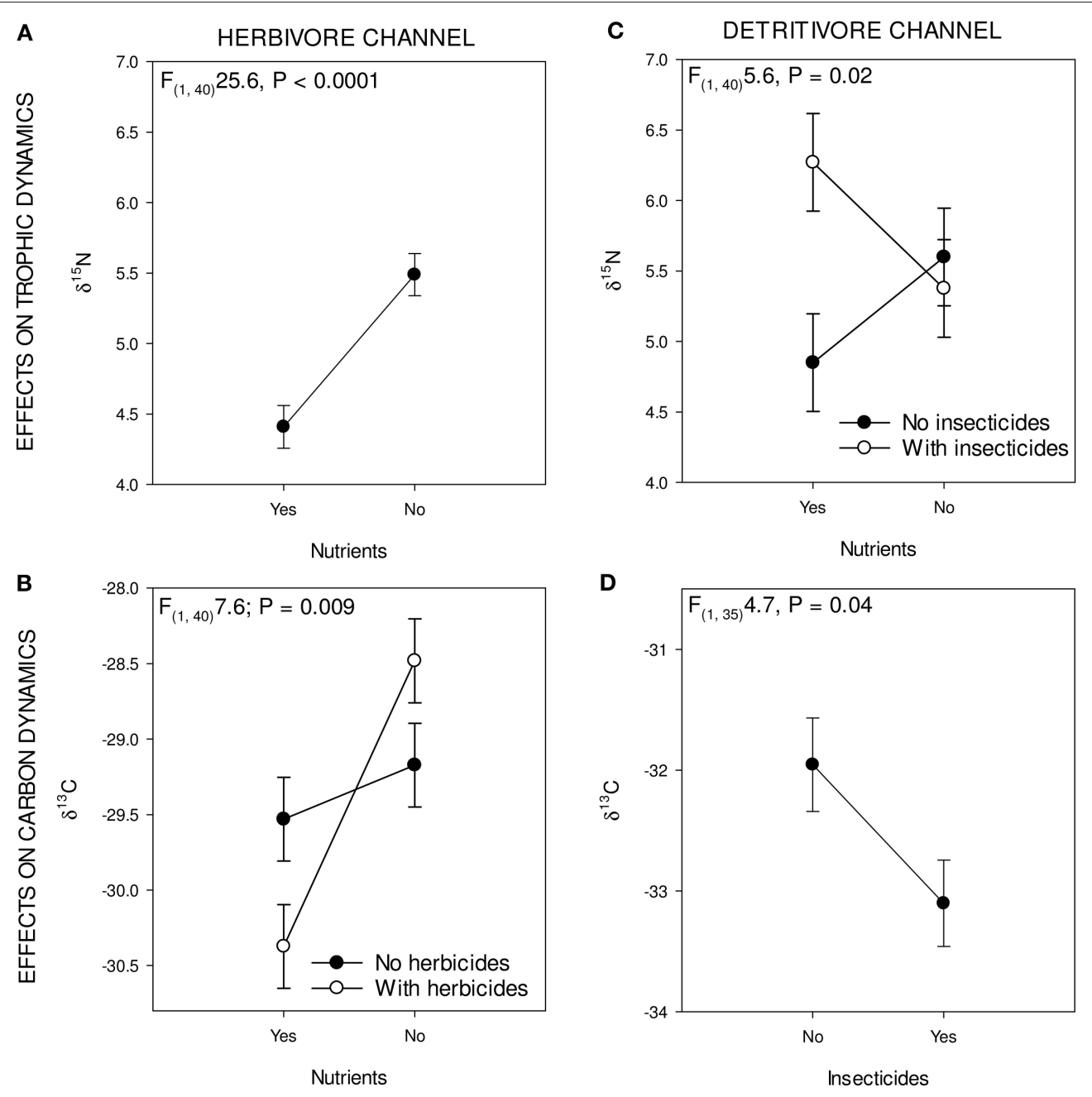

FIGURE 2 | Figure showing the significant treatment effect on the green and brown parts of the food web: upper two $(\mathbf{A}, \mathbf{B})$ showing effects of treatments on trophic level $\left(\delta^{15} \mathrm{~N} /{ }^{14} \mathrm{~N}\right)$ and lower two $(\mathbf{C}, \mathbf{D})$ illustrate the effect on food source $\left(\delta^{13} \mathrm{C} /{ }^{12} \mathrm{C}\right)$ for green and brown.
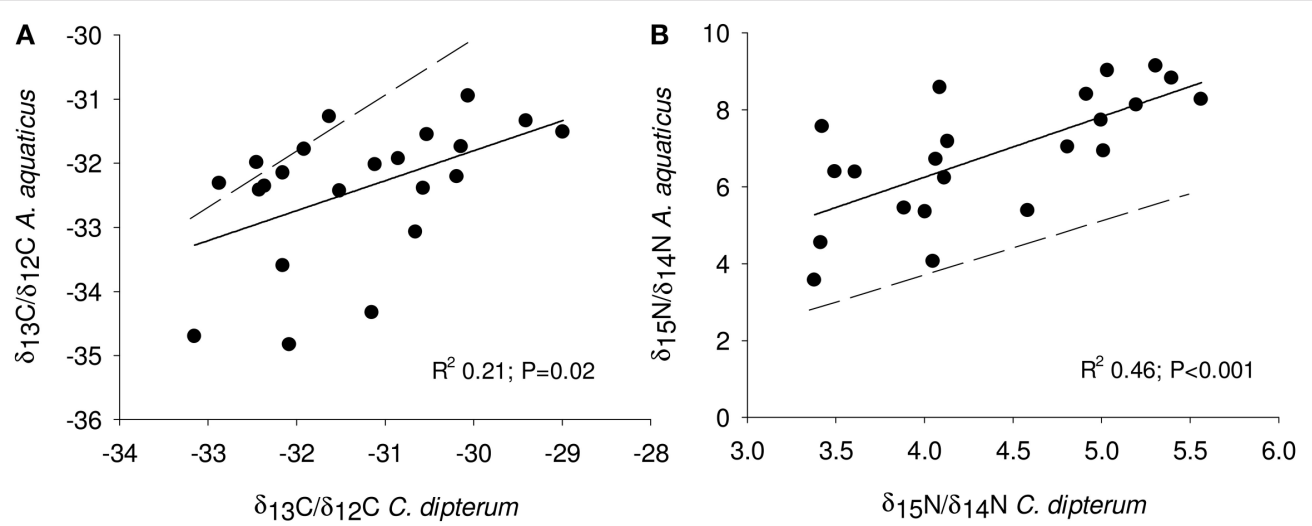

FIGURE 3 | Linear least square regression of nitrogen (A) and carbon (B) isotopes between A. aquaticus and C. dipterum. Line fit, $R^{2}$ and significance level are depicted in both panels. Dotted line indicates hypothetical 1:1 relationship between $A$. aquaticus and $C$. dipterum. 
ratio of $C$. dipterum $\left[F_{(1,18)} 8.9 ; P=0.008\right]$, whereas herbicides had a positive effect $\left[F_{(1,18)} 5.0 ; P=0.04\right]$. Moreover, we found an interaction effect between herbicides and nutrients $\left[F_{(1,18)} 6.7, P=0.02\right]$, where the effect of nutrients was larger when herbicides were added. Nutrient additions led to a significantly decreased $\delta^{15} \mathrm{~N} / \delta^{14} \mathrm{~N}$ ratio in $C$. dipterum $\left[F_{(1,18)} 10.084 ; P=0.005\right]$, but we found no effect of insecticide or herbicide additions on nitrogen isotope ratio.

As indicated by the high $\delta^{15} \mathrm{~N} / \delta^{14} \mathrm{~N}$ levels, $N$. glauca was the top predator (Figure 1). We found no significant effect of any of the treatments on both Hemiptera species (S. striata, N. glauca) (Tables 1, 2).

\section{DISCUSSION}

By studying the single and joint effects of stressors at environmentally realistic concentrations to an aquatic food web, we show that a number of key species in the community can alter their trophic position and food source as a result of the different stressors. Herbivorous species reacted mainly to the nutrients and herbicides and the synergistic interaction between these, while species in the detritivore part of the food web were observed to be affected by insecticide applications and interactions with nutrients. This suggests that there are qualitatively different effects of stressors on the different functional parts (green and brown) of the food web. This may have strong implications for our understanding of the effects of pesticides and nutrients on key ecosystem processes (Gessner and Tlili, 2016). However, the observed strong interactions between different pesticide classes and nutrients for the different parts of the aquatic food web also present us with a puzzle: we have no clear explanations for the second and third-order effects that go beyond mere speculation. These effects observed in a quasi-natural setting differ markedly and qualitatively from laboratory incubations which show isolated effects on individual species (Salminen et al., 1996; Song et al., 1997; Stoughton et al., 2008), and indicate that effects on species can feed through to higher levels of organization in aquatic ecosystems, and likely inherent ecosystem processes, as described in Mills et al. (1993) and Relyea and Hoverman (2006).

The observed shifts in trophic position and food source suggest that effects of pesticides can cause a rippling effect in the trophic linkages of the food web, depending whether or not excess nutrients are present. In this study, this effect was most pronounced in $A$. aquaticus and $L$. stagnalis. Our results show that the trophic level of $A$. aquaticus was considerably higher than expected based on literature (Graça et al., 1993). While the other detritivores (C. riparius, Tubifex sp.) had $\delta^{15} \mathrm{~N} / \delta{ }^{14} \mathrm{~N}$-levels of around $4.5-5, \delta^{15} \mathrm{~N} / \delta{ }^{14} \mathrm{~N}$-levels of $A$. aquaticus were almost a full trophic level higher. We suggest that this unexpected finding may be explained by the shift in diet from detritus-feeding to feeding on animal remains. Indeed, C. dipterum (and S. striata) exhibited a great population decline in all mesocosms. Similarly, we find that the trophic position of L. stagnalis depended strongly on input of insecticides. Presence of insecticides leads to an increase in trophic level for this species, which also indicates a shift in diet toward feeding on animal remains. The observed changes in food source and trophic level of A. aquaticus and L. stagnalis suggest a more general ecosystem phenomenon: that pesticides, through their effects on trophic linkages (Moore et al., 2005; Jabiol et al., 2013), can induce food web wide effects by rippling through the food web. Moreover, as these animals represent a significant part of temperate freshwater food webs, this indicates a potential for trophic transfer of toxicants (e.g., bioaccumulation, biomagnification), which in turn might affect species at higher trophic levels.

This study used a simplified community and setting and therefore it remains questionable whether the observed patterns also hold true for natural environments. The mesocosm approach that we chose for this study lacks a number of crucial elements of real ecosystems, most notably, it lacks actual sediments, has relatively low species densities and lacks dispersal: influx and outflux of species (Rohr et al., 2006; van den Brink, 2006). Species replacement is a powerful way to deal with changes in pressures, and could potentially dampen some of the observed effects. Not accounting for this complexity may have resulted in an overestimated toxicity in our setup, yet the emerging pattern that combined toxicity can differentially affect trophic linkages is likely equally relevant in natural environments, suggesting that a consideration of ecosystem complexity is warranted to obtain a more reliable understanding of how stressors can affect species and propagate through the environment.

\section{CONCLUSION}

This study shows that agricultural pressures and interactions between these pressures can induce shifts in trophic linkages in a simplified, model aquatic food web, and highlights that interactions between stressors can variably affect trophic linkages and can cascade toward ecosystem attributes that are essentially not targeted by the chemical pressures used in this study. These types of antagonistic and synergistic interactions are increasingly found to be potentially important explanations for the apparently unpredictable responses of ecosystem properties and processes to anthropogenic pressures, and have important implications for our understanding of how chemical stressors can propagate through food webs (e.g., bio-accumulation and biomagnification) with inherent risks for their functioning and the services they provide.

\section{AUTHOR CONTRIBUTION}

The ideas for this study were conceived by MS, PvB, MV, SB and EH; MS, SB and RvL carried out data collection; data analysis was performed by RvL, SB, MS, and $\mathrm{EH}$, and manuscript writing was carried out by MS, SB, and $\mathrm{EH}$ with structural comments from $\mathrm{MV}$ and PvB.

\section{ACKNOWLEDGMENTS}

We are grateful to the Hortus Botanicus in Leiden for providing the space and help to run this experiment, most notably Prof Paul Keßler and Theo Houthoff. We would 
like to thank Rody Blom, Arjen van Putten, and Erik Gertenaar for practical assistance and colleagues at the CML for their help with collecting the data. SB, EH, and MV were funded by NWO-ASPASIA and NWO-VIDI 864.13.010 granted to MV.

\section{REFERENCES}

Ahlgren, G., Lundstedt, L., Brett, M., and Forsberg, C. (1990). Lipid composition and food quality of some freshwater phytoplankton for cladoceran zooplankters. J. Plankton Res. 12, 809-818. doi: 10.1093/plankt/12.4.809

Altenburger, R., Backhaus, T., Boedeker, W., Faust, M., Scholze, M., and Grimme, L. H. (2000). Predictability of the toxicity of multiple chemical mixtures to Vibrio fischeri: mixtures composed of similarly acting chemicals. Environ. Toxicol. Chem.19, 2341-2347. doi: 10.1002/etc.5620190926

Backhaus, T., Faust, M., Scholze, M., Gramatica, P., Vighi, M., and Grimme, L. H. (2004). Joint algal toxicity of phenylurea herbicides is equally predictable by concentration addition and independent action. Environ. Toxicol. Chem. 23, 258-264. doi: 10.1897/02-497

Cairns, J. Jr. (1983). Are single species toxicity tests alone adequate for estimating environmental hazard? Hydrobiologia 100, 47-57. doi: 10.1007/BF00027421

Calow, P., and Forbes, V. E. (2003). Peer reviewed: does ecotoxicology inform ecological risk assessment? Environ. Sci. Technol. 37, 146A-151A. doi: 10.1021/es0324003

Cockrell, B. J. (1984). Effects of water depth on choice of spatially separated prey by Notonecta glauca L. Oecologia 62, 256-261. doi: 10.1007/BF00379023

Corvalan, C., Hales, S., and McMichael, A. (2005). Millenium Ecosystem Assessment. Ecosystems and Human well-being: Health Synthesis. Geneve: World Health Organization.

Côté, I. M., Darling, E. S., and Brown, C. J. (2016). Interactions among ecosystem stressors and their importance in conservation. Proc. R. Soc. B Biol. Sci. 283, 20152592. doi: 10.1098/rspb.2015.2592

David, J.-P., Rey, D., Pautou, M.-P., and Meyran, J.-C. (2000). Differential toxicity of leaf litter to dipteran larvae of mosquito developmental sites. J. Invertebr. Pathol. 75, 9-18. doi: 10.1006/jipa.1999.4886

Fleeger, J. W., Carman, K. R., and Nisbet, R. M. (2003). Indirect effects of contaminants in aquatic ecosystems. Sci. Total Environ. 317, 207-233. doi: 10.1016/S0048-9697(03)00141-4

Gagic, V., Kleijn, D., Báldi, A., Boros, G., Jørgensen, H. B., Elek, Z., et al. (2017). Combined effects of agrochemicals and ecosystem services on crop yield across Europe. Ecol. Lett. 20, 1427-1436. doi: 10.1111/ele.12850

Gessner, M. O., Swan, C. M., Dang, C. K., McKie, B. G., Bardgett, R. D., Wall, D. H., et al. (2010). Diversity meets decomposition. Trends Ecol. Evol. 25, 372-380. doi: 10.1016/j.tree.2010.01.010

Gessner, M. O., and Tlili, A. (2016). Fostering integration of freshwater ecology with ecotoxicology. Freshw. Biol. 61, 1991-2001. doi: 10.1111/fwb.12852

Graça, M. A., Maltby, L., and Calow, P. (1993). Importance of fungi in the diet of Gammarus pulex and Asellus aquaticus I: feeding strategies. Oecologia 93, 139-144. doi: 10.1007/BF00321203

Groendahl, S., and Fink, P. (2016). The effect of diet mixing on a nonselective herbivore. PLoS ONE 11:e0158924. doi: 10.1371/journal.pone.0158924

Hamilton, S. K., and Lewis, W. M. (1992). Stable carbon and nitrogen isotopes in algae and detritus from the Orinoco River floodplain, Venezuela. Geochim. Cosmochim. Acta 56, 4237-4246. doi: 10.1016/0016-7037(92)90264-J

Helweg, C., Mogensen, B. B., and Sørensen, P. B. (2003). Fate of Pesticides in Surface Waters, Laboraty and Field Experiments. Kopenhagen: Ministry of the Environment, Danish Environmental Protection Agency.

Hinkle-Conn, C., Fleeger, J. W., Gregg, J. C., and Carman, K. R. (1998). Effects of sediment-bound polycyclic aromatic hydrocarbons on feeding behavior in juvenile spot (Leiostomus xanthurus Lacepede: Pisces). J. Exp. Mar. Biol. Ecol. 227, 113-132. doi: 10.1016/S0022-0981(97)00265-7

Hobson, K. A., and Welch, H. E. (1992). Determination of trophic relationships within a high Arctic marine food web using $\delta^{13} \mathrm{C}$ and $\delta^{15} \mathrm{~N}$ analysis. Mar. Ecol. Prog. Ser. 84, 9-18.

Hunting, E. R., Mulder, C., Kraak, M. H. S., Breure, A. M., and Admiraal, W. (2013). Effects of copper on invertebrate-sediment

\section{SUPPLEMENTARY MATERIAL}

The Supplementary Material for this article can be found online at: https://www.frontiersin.org/articles/10.3389/fenvs. 2017.00075/full\#supplementary-material

interactions. Environ. Pollut. 180, 131-135. doi: 10.1016/j.envpol.2013. 05.027

Ieromina, O., Peijnenburg, W. J. G. M., Musters, C. J. M., and Vijver, M. G. (2016). The effect of pesticides on the composition of aquatic macrofauna communities in field ditches. Basic Appl. Ecol. 17, 125-133. doi: 10.1016/j.baae.2015.08.002

Jabiol, J., Mckie, B. G., Bruder, A., Bernadet, C., Gessner, M. O., and Chauvet, E. (2013). Trophic complexity enhances ecosystem functioning in an aquatic detritus-based model system. J. Anim. Ecol. 82, 1042-1051. doi: 10.1111/1365-2656.12079

Kimball, K. D., and Levin, S. A. (1985). Limitations of laboratory bioassays: the need for ecosystem-level testing. Bioscience 35, 165-171. doi: 10.2307/1309866

Klecka, J., and Boukal, D. S. (2012). Who eats whom in a pool? a comparative study of prey selectivity by predatory aquatic insects. PLOS ONE 7:e37741. doi: 10.1371/journal.pone.0037741

Mills, L. S., Soule, M. E., and Doak, D. F. (1993). The keystone-species concept in ecology and conservation. BioScience 43, 219-224. doi: 10.2307/1312122

Moore, J. C., McCann, K., and De Ruiter, P. C. (2005). Modeling trophic pathways, nutrient cycling, and dynamic stability in soils. Pedobiologia 49, 499-510. doi: 10.1016/j.pedobi.2005.05.008

Ormerod, S. J., Dobson, M., Hildrew, A. G., and Townsend, C. R. (2010). Multiple stressors in freshwater ecosystems. Freshw. Biol. 55, 1-4. doi: 10.1111/j.1365-2427.2009.02395.x

Pesticide Atlas, version 2.0. (2015). Leiden University (CML) and RijkswaterstaatWVL. Leiden. Available online at: www.bestrijdingsmiddelenatlas.nl (Accessed Feb 2, 2016).

Pimm, S. L., Lawton, J. H., and Cohen, J. E. (1991). Food web patterns and their consequences. Nature 350, 669-674. doi: 10.1038/350669a0

Post, D. M. (2002). Using stable isotopes to estimate trophic position: models, methods, and assumptions. Ecology 83, 703-718. doi: 10.1890/0012-9658(2002)083[0703:USITET]2.0.CO;2

Relyea, R., and Hoverman, J. (2006). Assessing the ecology in ecotoxicology: a review and synthesis in freshwater systems. Ecol. Lett. 9, 1157-1171. doi: 10.1111/j.1461-0248.2006.00966.x

Rohr, J. R., Kerby, J. L., and Sih, A. (2006). Community ecology as a framework for predicting contaminant effects. Trends Ecol. Evol. 21, 606-613. doi: 10.1016/j.tree.2006.07.002

Salminen, J., Eriksson, I., and Haimi, J. (1996). Effects of terbuthylazine on soil fauna and decomposition processes. Ecotoxicol. Environ. Saf. 34, 184-189. doi: 10.1006/eesa.1996.0062

Santer, B., and Van Den Bosch F. (1994). Herbivorous nutrition of Cyclops vicinus: the effect of a pure algal diet on feeding, development, reproduction and life cycle. J. Plankton Res. 16, 171-195. doi: 10.1093/plankt/16.2.171

Schulz, R., and Dabrowski, J. M. (2001). Combined effects of predatory fish and sublethal pesticide contamination on the behavior and mortality of mayfly nymphs. Environ. Toxicol. Chem. 20, 2537-2543. doi: 10.1002/etc.5620201120

Smith, G. M., and Weis, J. S. (1997). Predator-prey relationships in mummichogs (Fundulus heteroclitus (L.)): effects of living in a polluted environment. J. Exp. Mar. Biol. Ecol. 209, 75-87. doi: 10.1016/S0022-0981(96)02590-7

Song, M. Y., Stark, J. D., and Brown, J. J. (1997). Comparative toxicity of four insecticides, including imidacloprid and tebufenozide, to four aquatic arthropods. Environ. Toxicol. Chem. 16, 2494-2500. doi: 10.1002/etc.5620161209

Stoughton, S. J., Liber, K., Culp, J., and Cessna, A. (2008). Acute and chronic toxicity of imidacloprid to the aquatic invertebrates Chironomus tentans and Hyalella azteca under constant-and pulse-exposure conditions. Arch. Environ. Contam. Toxicol. 54, 662-673. doi: 10.1007/s00244-007-9073-6

van den Brink, P. J. (2006). Response to recent criticism on aquatic semifield experiments: opportunities for new developments in ecological risk assessment of pesticides. Integr. Environ. Assess. Manag. 2, 202. doi: 10.1002/ieam.5630020302 
Vijver, M. G., Hunting, E. R., Nederstigt, T. A., Tamis, W. L., van den Brink, P. J., and van Bodegom, P. M. (2017). Postregistration monitoring of pesticides is urgently required to protect ecosystems. Environ. Toxicol. Chem. 36, 860-865. doi: $10.1002 /$ etc. 3721

Vörösmarty, C. J., McIntyre, P. B., Gessner, M. O., Dudgeon, D., Prusevich, A., Green, P., et al. (2010). Global threats to human water security and river biodiversity. Nature 467, 555-561. doi: 10.1038/nature09440

Wallace, J. B., Eggert, S. L., Meyer, J. L., and Webster, J. R. (1997). Multiple trophic levels of a forest stream linked to terrestrial litter inputs. Science 277, 102-104. doi: $10.1126 /$ science.277.5322.102

Wilbur, H. M., and Dec, N. (1997). Experimental ecology of food webs: complex systems in temporary ponds. Ecology 78, 2279-2302. doi: 10.1890/00129658(1997)078[2279:EEOFWC]2.0.CO2
Conflict of Interest Statement: The authors declare that the research was conducted in the absence of any commercial or financial relationships that could be construed as a potential conflict of interest.

The reviewer, VG, and handling Editor declared their shared affiliation.

Copyright (๑) 2017 Schrama, Barmentlo, Hunting, van Logtestijn, Vijver and van Bodegom. This is an open-access article distributed under the terms of the Creative Commons Attribution License (CC BY). The use, distribution or reproduction in other forums is permitted, provided the original author(s) or licensor are credited and that the original publication in this journal is cited, in accordance with accepted academic practice. No use, distribution or reproduction is permitted which does not comply with these terms. 